\title{
Cervical screening uptake and its predictors among rural women in Malaysia
}

\author{
Daniel Eng Hwee $\underline{G a n}^{1}$, MBBs, Maznah Dahluí2, MD, PhD
}

INTRODUCTION Cervical cancer is the third most common cancer among Malaysian women. However, the uptake of cervical cancer screening - Pap smear - by women in Malaysia has been low and remains a challenge. This study was conducted to assess the cervical screening practices of rural women in Malaysia and to examine the factors associated with such practices.

METHODS A cross-sectional survey was conducted in five rural districts in Perak, Malaysia. 1,000 households were selected through multistage random sampling. Women aged 20-64 years were interviewed by trained enumerators using structured questionnaires. Binomial logistic regression was used to identify predictors of cervical screening through univariate and multivariate analyses.

RESULTS Among the 959 respondents, only 48.9\% had undergone Pap smear at least once in the past three years. Women in the age group 40-49 years (odds ratio 3.027, 95\% confidence interval 1.546-5.925; $p<0.005$ ) were found to be significantly more likely to attend cervical cancer screening as compared to those in the age group 20-29 years. Other significant predictors were being married with children, having knowledge of cervical cancer symptoms, receiving relevant information regarding cervical cancer from health personnel or campaigns, being engaged in family planning and receiving encouragement from husbands.

CONCLUSION Efforts to boost the uptake of Pap smear screening among the rural population should be targeted toward the predictors of positive uptake.

Keywords: cervical screening practices, Pap smear, predictors

\section{INTRODUCTION}

Cervical cancer ranks as the third most common cancer among women in the world $^{(1)}$ and is also the third most common cancer among women in Malaysia.(2) Since 1980, the global incidence of cervical cancer has increased from 378,000 (range $256,000-489,000$ ) to 454,000 (range $318,000-620,000$ ), with an average annual increase of $0.6 \%{ }^{(3)} 85 \%$ of its burden occurs in developing countries, where it accounts for $13 \%$ of all cancers in women. ${ }^{(1)}$ The mortality of cervical cancer has increased from 174,000 deaths in 1980 to 200,000 deaths in 2010, with an annual increase of $0.46 \% .{ }^{(3)}$ Mortality from cervical cancer is higher in Southeast Asian countries than in Western Europe, North America, Australasia and high-income Asia Pacific regions, and is second only to that in the South Asia region. ${ }^{(3)}$

The age standardised ratio (ASR) in Malaysia was 7.8 per 100,000 population, with those of Indian ethnicity recording the highest ASR (10.3 per 100,000 population), followed by the Chinese (9.5 per 100,000 population) and Malay (5.3 per 100,000 population) races. ${ }^{(2)}$ Cervical cancer was more common among the elderly, with peak incidence seen among women aged 60-69 years. ${ }^{(2)}$ In 2010, the probability of death among Malaysian women due to cervical cancer was 0.7 of the global population. The percentage of patients in Malaysia diagnosed with stage 3 and stage 4 cervical cancer was $26 \%$ and $19 \%$, respectively. ${ }^{(2)}$

Since the 1960s, Malaysia has been implementing opportunistic Pap smear for all sexually active women aged 20-65 years. ${ }^{(4)}$ According to the 2006 National Health and Morbidity Survey (NHMS III), only $47.3 \%$ of Malaysian women have ever undergone Pap smear screening. ${ }^{(5)}$ Other local studies have found that the uptake of Pap smear screening was $25 \%$ among factory workers $^{(6)}$ and $38 \%$ among urban school teachers, ${ }^{(7)}$ revealing figures that were much lower than countries with population screening programmes. Poor knowledge of cervical cancer prevention was also noted among students in a local university. ${ }^{(8)}$ Limited access to healthcare, poor access to information and empowerment, and poverty have been identified as barriers to cervical cancer screening uptake. These factors are likely to bear their greatest effects on rural communities. ${ }^{(9)}$ It is thus vital to not only evaluate the cervical screening practices among this underserved community, but also to identify the positive and negative factors that may be associated with their compliance, so that more targeted approaches can be initiated to address poor screening attendance among women from these communities.

Previous research has placed great focus on factors hindering women from attending cervical cancer screening. ${ }^{(10)}$ Therefore, this study aimed to measure the prevalence of Pap smear screening uptake among the rural population in Malaysia, and to identify the socioeconomic and awareness factors associated with the uptake of cervical cancer screening in this cohort.

\section{METHODS}

Perak has a total population of 2,258,428, with an ethnic breakdown of Malay $(50 \%-80 \%)$, Chinese $(15 \%-30 \%)$, Indian

Department of Social and Preventive Medicine, Faculty of Medicine, ${ }^{2}$ Centre for Population Health, University of Malaya, Kuala Lumpur, Malaysia

Correspondence: Dr Maznah Dahlui, Associate Professor, Centre for Population Health, University of Malaya, Kuala Lumpur 50602, Malaysia. maznahd@ummc.edu.my 
$(5 \%-15 \%)$, and a small proportion of indigenous groups and others such as those of Siamese descent. ${ }^{(11)}$ About $65 \%$ of the population falls into the age group 15-64 years. Rural districts such as those in Northern Perak, which make up the third largest portion of Perak's economy, are highly reliant on agriculture. This cross-sectional study was conducted in five rural districts in Northern Perak, namely Kuala Kangsar, Taiping, Kerian, Kampar and Grik.

A total of 1,000 households were selected through multistage random sampling. Women aged 20-64 years were interviewed using structured questionnaires by trained enumerators. Inclusion criteria other than age were: (a) having resided in the village for $\geq 6$ months; (b) available at the time of house visit; and (c) agreeable to participating in the study. Women with known psychiatric illnesses were excluded. The response rate was 100\%, since the interviews were conducted at the women's homes and visits were repeated until the women were available for interview. The questionnaires used in this study were modified from the questionnaires used and pretested in a community residency programme among the rural population in Central Perak. Based on the findings of previous studies, four variables were identified as the predictors of cervical screening uptake - sociodemographic factors, knowledge of cervical cancer, attitudes toward screening and social support from husbands for screening. ${ }^{(6,7,70)}$

Recorded data were analysed using the Statistical Package for the Social Sciences for Windows version 16.0 (SPSS Inc, Chicago, IL, USA). Categorical data were described in terms of rates and percentages. Interval data were described using mean and median values. Regression analysis was used to identify the predictors of uptake of Pap smear screening. A p-value $<0.05$ was set as the level of significant difference between two variables. Variables with $\mathrm{p}<0.05$ on univariate analysis were included in the multivariate analysis in order to identify the strongest predictors of cervical cancer screening and to adjust for confounding factors.

Ethical approval was obtained from the Ethics Committee of University of Malaya Medical Centre. Written informed consent was obtained from all the respondents, and the nature of the survey was explained to them prior to the study. Respondents were free to decline participation in the study.

\section{RESULTS}

Of the 1,000 households approached, 959 women were included in this study. Of the 901 women who were excluded, 585 (64.9\%) were $<20$ years old, while 316 (35.1\%) were $>64$ years old; of these, $744(82.6 \%)$ were Malay, $97(10.8 \%)$ were Chinese, $33(3.7 \%)$ were Indian, $17(1.9 \%)$ belonged to the aboriginal ethnic groups and $10(1.1 \%)$ belonged to other ethnic groups. The majority of women included in the study were aged $>40$ years (mean age $45.2 \pm 12.2$ years; range $20-64$ years). The ethnic distribution of the respondents was reflective of the population distribution seen in the Northern states of Malaysia. ${ }^{(11)} \mathrm{A}$ large proportion of the respondents were Malay $(80.8 \%)$, had at least
Table I. Sociodemographic characteristics of respondents ( $n=959)$.

\begin{tabular}{lc}
\hline Characteristic & No. (\%) \\
\hline Age group (yrs) & \\
$20-29$ & $145(15.1)$ \\
$30-39$ & $165(17.2)$ \\
$40-49$ & $231(24.1)$ \\
$50-59$ & $295(30.8)$ \\
$60-64$ & $123(12.8)$ \\
Ethnicity & \\
Malay & $775(80.8)$ \\
Chinese & $106(11.1)$ \\
Indian & $48(5.0)$ \\
Aboriginal & $16(1.7)$ \\
Other & $14(1.5)$ \\
Religion & \\
Islam & $780(81.3)$ \\
Christianity & $21(2.2)$ \\
Buddhism & $112(11.7)$ \\
Hinduism & $35(2.2)$ \\
Other & $11(1.1)$ \\
Educational level & \\
Never attended school & $89(9.3)$ \\
Primary education & $377(39.3)$ \\
Secondary education & $417(43.5)$ \\
Certificates/occupational skills & $40(4.2)$ \\
College/university education & $36(3.8)$ \\
Occupational status & \\
Not working & $601(62.7)$ \\
Working & $358(37.3)$ \\
Marital status & \\
Single/never married & $185(19.3)$ \\
Married & $774(80.7)$ \\
Parity & \\
0 & $151(15.7)$ \\
1 & $66(6.9)$ \\
$2-3$ & $228(23.8)$ \\
$\geq 4$ & $514(53.6)$ \\
\hline & \\
\hline & \\
& \\
&
\end{tabular}

secondary education (secondary or higher $51.5 \%$ ), were not working $(62.7 \%)$ and were married with spouses (80.7\%) (Table I). More than $50 \%$ of the women had $\geq 4$ children and only $15.7 \%$ of them had no children.

Among the women surveyed, only $10.2 \%$ of them were using family planning methods such as condoms or oral contraceptive pills at the time of the survey (Table II). The majority of respondents (490/959, 51.1\%) had never had a Pap smear, and over 30\% of them $(n=291)$ had never heard of Pap smear screening. Among the respondents who had ever had a Pap smear, 24.9\% underwent Pap smears annually, 5.6\% once in every two years and $18.4 \%$ once every three years. The level of misconception among women regarding the symptoms of cervical cancer was high, as most women cited irregular menses $(12.4 \%)$, foul-smelling vaginal discharge $(6.0 \%)$ and pelvic pain $(4.1 \%)$ as symptoms of cervical cancer. In all, 596 (62.1\%) respondents could not name any symptoms suggestive of cervical cancer. Understanding of the risk factors of cervical cancer was also very poor among the women surveyed, as $78.3 \%$ of respondents $(n=751)$ did not know any risk factors of cervical cancer, while another $6.3 \%(n=60)$ attributed family history as a risk factor of cervical cancer. 
Table II. Knowledge and behavioural patterns of respondents (n = 959).

\begin{tabular}{|c|c|}
\hline Characteristic & No. (\%) \\
\hline \multicolumn{2}{|l|}{ Frequency of Pap smear screening } \\
\hline Never & $490(51.1)$ \\
\hline Annually & $239(24.9)$ \\
\hline Once every two years & $54(5.6)$ \\
\hline Once every three years & $176(18.4)$ \\
\hline \multicolumn{2}{|l|}{ Symptoms of cervical cancer } \\
\hline Irregular menses & $119(12.4)$ \\
\hline Intermenstrual bleed & $75(7.8)$ \\
\hline Postcoital bleed & $26(2.7)$ \\
\hline Vaginal discharge & $2(0.2)$ \\
\hline Foul-smelling vaginal discharge & $57(6.0)$ \\
\hline Pelvic pain & $39(4.1)$ \\
\hline Others & $45(4.7)$ \\
\hline Don't know & $596(62.1)$ \\
\hline \multicolumn{2}{|l|}{ Risk factors of cervical cancer } \\
\hline Sexual promiscuity & $143(14.9)$ \\
\hline Family history & $60(6.3)$ \\
\hline Uncircumcised partner & $5(0.5)$ \\
\hline Don't know & $751(78.3)$ \\
\hline \multicolumn{2}{|c|}{ Sources of information on cervical cancer } \\
\hline Health personnel & $432(45.0)$ \\
\hline Health campaigns/brochures & $78(8.1)$ \\
\hline Friends/relatives & $80(8.3)$ \\
\hline Mass media & $88(9.2)$ \\
\hline None & $281(29.3)$ \\
\hline \multicolumn{2}{|l|}{ Family planning } \\
\hline No & $861(89.8)$ \\
\hline Yes & $98(10.2)$ \\
\hline \multicolumn{2}{|c|}{ Comfortable with male doctor performing Pap smear } \\
\hline No & $474(49.4)$ \\
\hline Yes & $485(50.6)$ \\
\hline \multicolumn{2}{|c|}{ If symptomatic, who would be approached first } \\
\hline Nobody & $100(10.4)$ \\
\hline Husband & $584(60.9)$ \\
\hline Mother & $96(10.0)$ \\
\hline Sister & $54(5.6)$ \\
\hline Friends & $19(2.0)$ \\
\hline Children & $53(5.5)$ \\
\hline Doctor & $36(3.8)$ \\
\hline Others & $17(1.8)$ \\
\hline \multicolumn{2}{|l|}{ Support needed } \\
\hline None & $98(10.3)$ \\
\hline Moral support & $583(60.7)$ \\
\hline Physical support & $161(16.8)$ \\
\hline Information & $59(6.2)$ \\
\hline Financial support & $23(2.4)$ \\
\hline Others & $35(3.6)$ \\
\hline
\end{tabular}

Most of the respondents' sources of information on cervical cancer was the government or private health personnel (45.0\%), followed by the mass media $(9.2 \%)$, health campaigns or brochures $(8.1 \%)$, and friends or relatives $(8.3 \%)$. About $30 \%$ of the respondents $(n=281)$ did not obtain any information on cervical cancer. When questioned about the preference of people they would approach first if they were to experience cervical cancer symptoms, the majority cited their husbands $(60.9 \%)$, followed by their mothers $(10.0 \%)$. While $10.4 \%$ of women responded that they would not consult anyone, only $3.8 \%$ of respondents named doctors as the first person they would approach. On the types of support most desired by women for attending screening programmes, $60.7 \%$ of the women claimed to need moral support and another $16.8 \%$ cited physical support such as transport and companions.

Table III shows the predictors of Pap smear attendance among the respondents. On multivariate analysis, women aged 40-49 years (odds ratio [OR] 3.027, 95\% confidence interval [CI] 1.546-5.925; $p=0.001$ ) were found to be significantly more likely to attend cervical cancer screening when compared to those aged 20-29 years. Other age groups failed to show any significance. Although women of Chinese ethnicity were found to be less likely to attend Pap smear screening when compared to Malay women on univariate analysis, this association was not found to be significant after other factors were taken into account on multivariate analysis. Parity was found to be an important factor in determining Pap smear attendance, as women with one child (OR 5.335, 95\% Cl 2.162-13.166; $\mathrm{p}<0.001$ ), two to three children (OR 4.036, 95\% Cl 1.947-8.364; $\mathrm{p}<0.001)$, and four or more children (OR 4.935, 95\% Cl 2.35210.357; $\mathrm{p}<0.001$ ) were more likely to attend Pap smear screening when compared to women who did not have any children. However, no rising trend in the odds was observed between the groups for this variable. Marital status was a strong predictor of cervical cancer screening on univariate analysis (OR 4.021, 95\% Cl 2.780-5.818; $\mathrm{p}<0.001)$, although the association was not found to be significant on multivariate analysis. Educational level above primary education, employment and having chronic diseases were not predictors of Pap smear attendance on multivariate analysis.

Women who were able to name symptoms of cervical cancer correctly (OR 1.845, 95\% Cl 1.056-3.224; $\mathrm{p}=0.031$ ), women on family planning at the time of the study (OR 2.240, 95\% CI 1.149-4.365; $p=0.018$ ), and women who received social support from their husbands for screening (OR 2.109, 95\% Cl 1.442-3.086; $\mathrm{p}<0.001)$ were significantly associated with attendance of Pap smear screening. Women who received information about cervical cancer were also more likely to attend Pap smear screening. The odds were highest among women whose source of information on cervical cancer was the government or private health personnel (OR 44.878, 95\% Cl 22.865-88.084; $\mathrm{p}<0.001)$, followed by health campaigns or brochures (OR 39.666, 95\% Cl 17.319-90.852; p < 0.001), and the mass media (OR 21.448, 95\% Cl 9.690-47.496; $p<0.001$ ). Sharing of information among friends and relatives (OR 19.084, 95\% Cl 8.540-42.646; $\mathrm{p}<0.001$ ) was also strongly associated with attendance of Pap smear screening. Variables such as agreeable to male doctors performing Pap smear, willingness to approach someone (such as husband or siblings) when experiencing cervical cancer symptoms, and the ability to identify the risk factors of cervical cancer were not associated with Pap smear screening attendance.

\section{DISCUSSION}

The percentage of women who had undergone Pap smear was less than $50 \%$ in our cohort from rural Malaysia. This finding is 
Table III. Predictors of Pap smear uptake among respondents.

\begin{tabular}{|c|c|c|c|c|}
\hline \multirow[t]{2}{*}{ Variable } & \multicolumn{2}{|c|}{ Univariate analysis } & \multicolumn{2}{|c|}{ Multivariate analysis } \\
\hline & OR $(95 \% \mathrm{Cl})$ & p-value & OR $(95 \% \mathrm{Cl})$ & p-value \\
\hline \multicolumn{5}{|l|}{ Sociodemographics } \\
\hline \multicolumn{5}{|l|}{ Age group* (yrs) } \\
\hline $30-39$ & $3.743(2.329-6.016)$ & $<0.001$ & $1.860(0.958-3.610)$ & 0.067 \\
\hline $40-49$ & $4.393(2.809-6.870)$ & $<0.001$ & $3.027(1.546-5.925)$ & 0.001 \\
\hline $50-59$ & $2.085(1.365-3.184)$ & 0.001 & $1.644(0.831-3.255)$ & 0.153 \\
\hline $60-64$ & $0.982(0.579-1.663)$ & 0.945 & $1.327(0.581-3.026)$ & 0.502 \\
\hline \multicolumn{5}{|l|}{ Ethnicity ${ }^{+}$} \\
\hline Chinese & $0.626(0.413-0.948)$ & 0.027 & $0.776(0.435-1.385)$ & 0.391 \\
\hline Indian & $0.650(0.358-1.179)$ & 0.156 & $1.236(0.505-3.025)$ & 0.643 \\
\hline Indigenous groups & $4.300(1.216-15.208)$ & 0.024 & $2.966(0.470-18.719)$ & 0.247 \\
\hline Others (i.e. Siamese) & $0.744(0.256-2.165)$ & 0.588 & $0.822(0.156-4.331)$ & 0.818 \\
\hline \multicolumn{5}{|l|}{ Parity ${ }^{*}$} \\
\hline 1 & $7.844(3.966-15.512)$ & $<0.001$ & $5.335(2.162-13.166)$ & $<0.001$ \\
\hline $2-3$ & $9.383(5.425-16.228)$ & $<0.001$ & $4.036(1.947-8.364)$ & $<0.001$ \\
\hline$>4$ & $8.511(5.104-14.193)$ & $<0.001$ & $4.935(2.352-10.357)$ & $<0.001$ \\
\hline Married & $4.021(2.780-5.818)$ & $<0.001$ & $1.662(1.001-2.761)$ & 0.05 \\
\hline Above primary education & $1.639(1.270-2.116)$ & $<0.001$ & $0.993(0.659-1.496)$ & 0.974 \\
\hline Employed & $0.970(0.747-1.260)$ & 0.820 & & \\
\hline Chronic disease & $1.264(0.963-1.659)$ & 0.092 & & \\
\hline \multicolumn{5}{|l|}{ Health factors } \\
\hline Ability to identify symptoms of cervical cancer & $2.651(1.713-4.103)$ & $<0.001$ & $1.845(1.056-3.224)$ & 0.031 \\
\hline \multicolumn{5}{|l|}{ Source of information on cervical cancer ${ }^{\S}$} \\
\hline Health personnel & $74.554(39.264-141.564)$ & $<0.001$ & $44.878(22.865-88.084)$ & $<0.001$ \\
\hline Health campaigns/brochures & $55.227(25.542-119.414)$ & $<0.001$ & $39.666(17.318-90.852)$ & $<0.001$ \\
\hline Friends/relatives & $20.083(9.518-42.372)$ & $<0.001$ & $19.084(8.540-42.646)$ & $<0.001$ \\
\hline Mass media & $22.411(10.759-46.681)$ & $<0.001$ & $21.448(9.690-47.476)$ & $<0.001$ \\
\hline Family planning & $6.307(3.630-10.956)$ & $<0.001$ & $2.240(1.149-4.365)$ & 0.018 \\
\hline Agreeable to male doctor performing Pap smear & $1.842(1.426-2.381)$ & $<0.001$ & $1.149(0.795-1.661)$ & 0.459 \\
\hline Approach others, if symptomatic & $2.559(1.628-4.022)$ & $<0.001$ & $0.676(0.340-1.346)$ & 0.265 \\
\hline Social support for screening & $4.208(3.198-5.536)$ & $<0.001$ & $2.109(1.442-3.086)$ & $<0.001$ \\
\hline Ability to identify risk factors of cervical cancer & $1.325(0.932-1.883)$ & 0.117 & & \\
\hline
\end{tabular}

${ }^{*}$ As compared to women aged $20-29$ years old. ${ }^{\dagger}$ As compared to the Malay majority. ${ }^{\ddagger}$ As compared to those without children. ${ }^{\S}$ As compared to respondents with no source of cervical cancer information

$\mathrm{Cl}$ : confidence interval; OR: odds ratio

similar to the rates of cervical screening uptake by women in Malaysia in general. ${ }^{(5)}$ Although our findings indicated a higher uptake of cervical screening by women compared to previous studies on Malaysian factory workers ${ }^{(6)}$ and school teachers, ${ }^{(7)}$ the figure is still worrying. Furthermore, these results are much lower than those from developed countries such as Finland, ${ }^{(12)}$ United Kingdom, ${ }^{(12)}$ the Netherlands ${ }^{(12)}$ and Hong Kong. ${ }^{(13)}$ In comparison with previous studies, ${ }^{(13-15)}$ our respondents' knowledge of cervical cancer was considered poor, as a majority of them could not name any symptom or risk factor of cervical cancer, and among respondents who could name the symptoms or risk factors, many had given wrong answers. A study among Turkish women by Uysal and Birsel reported that most of their respondents were able to relate abnormal vaginal bleeding and postcoital bleeding with cervical cancer. ${ }^{(16)}$ Therefore, our results highlight the need to improve awareness of cervical cancer and Pap smear screening among the rural population in Malaysia.

Women aged 40-49 years were found to be strongly associated with having a previous Pap smear when compared to those aged 20-29 years in our study. Age has been shown to be a significant factor for Pap smear attendance in other studies as well. ${ }^{(6,7,17-21)}$ Chinese women from rural areas were found to be less likely to attend cervical cancer screening compared to their Malay counterparts in our study, and this finding is in agreement with a study by Chee et al on factory workers. ${ }^{(6)}$ However, other local studies have reported that Malay women were less likely to attend cervical cancer screening. ${ }^{(7,14)}$ We also found that women with children were more likely to attend cervical cancer screening compared to those who did not have any offspring. Similar findings have been reported in previous studies on Malaysian and Norwegian women. ${ }^{(6,7,20)}$ This observation could be related to greater interaction between healthcare personnel and women with children who attend maternal and child health clinics, thus giving them more opportunities to gain awareness of cervical cancer and schedule appointments for cervical screening, if required.

Marital status was a significant predictor of cervical cancer screening in our study, even after adjusting for other factors such as age and parity. This result is in agreement with the findings of many studies. ${ }^{(6,20,15)}$ Educational level was another variable that was associated with the uptake of cervical cancer screening, although 
the correlation was not found to be statistically significant in our study. Such an association has also been reported in previous studies on Malaysian, Taiwanese, Norwegian and Argentinean

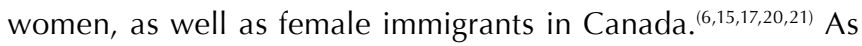
reported by two other studies, ${ }^{(15,17)}$ the employment status of women was also not associated with the uptake of cervical cancer screening in our study.

Women in our cohort who were able to name a symptom of cervical cancer, such as intermenstrual bleeding, postcoital bleeding and vaginal discharge, were found to be two times more likely to attend cervical cancer screening. Liao et al have also found the association between knowledge of cervical cancer and the uptake of screening to be statistically significant. ${ }^{(17)}$ Women who had sources of information pertaining to cervical cancer were also the most likely to attend screening than those who claimed to have no particular source of such information. Information from the government or private health personnel was the strongest predictor of cervical cancer screening uptake in our study, followed by information from health campaigns or health brochures, and the mass media. This finding was encouraging, as it reflects the effectiveness of government initiatives that use such channels of information to stimulate positive cervical screening behaviour among the rural population. The importance of providing women with adequate information on cervical cancer has also been emphasised by Abdullah et al, who reported that insufficient information provided by healthcare personnel was significantly associated with poor uptake of Pap smear screening among secondary school teachers in Malaysia. ${ }^{(7)}$ Based on the latest evidence, the Cancer Screening Uptake Expert Panel has recently recommended the use of small media and one-on-one education to increase the uptake of cervical cancer screening. ${ }^{(22)}$ Health professionals and healthcare workers should take the opportunity to educate and encourage women attending health facilities for other health problems to undergo cervical screening. It would be unfortunate if such opportunities are not availed, given that studies on Malaysian and Zimbabwean women have reported that the lack of recommendations from doctors was a contributory factor for the reluctance of women to attend regular Pap smear screening. ${ }^{(23,24)}$

The practice of contraception such as the use of condoms or oral contraceptive pills among women was found to be predictive of cervical screening attendance in our study, and this finding is in agreement with previous studies. ${ }^{(6)}$ However, studies by Abdullah et $\mathrm{al}^{(7)}$ and Hansen et $\mathrm{al}^{(20)}$ reported that the use of oral contraceptive pills was not a predictor of cervical screening attendance. Women in our study who claimed to receive social support from their husbands were two times more likely to attend cervical cancer screening. This finding may be reflective of the intrinsic elements of marriage, which may influence positive health behaviour among women, rather than just being associated with the status of being married. ${ }^{(25)}$ Other studies among Brazilian $^{(26)}$ and Argentinean ${ }^{(27)}$ women have also confirmed the positive impact of social support on adherence to cervical cancer screening. As previously explored, the need for social support - be it emotional or material - is a fact, ${ }^{(28)}$ and it is important that this area be given due prominence to ensure that efforts to enhance screening uptake among women in the rural setting are successful. Initiatives for education on cervical cancer and promotion of cervical cancer screening should not only be enhanced, but also targeted at men, especially husbands, so that they would encourage their partners to attend cervical cancer screening in addition to providing them with the necessary support.

As this study was conducted using a cross-sectional design, the authors were unable to determine if the uptake of cervical cancer screening among the women surveyed was a result of having knowledge regarding cervical cancer or whether this knowledge was acquired when they attended the screening. Nevertheless, this study has provided useful insights on the factors associated with the uptake of cervical cancer screening, and this knowledge will aid in designing public health intervention programmes intended to address the poor uptake of cervical cancer screening among women and in particular, rural women.

In conclusion, the results of this study reinforce the point that the prevalence of cervical cancer screening uptake among rural women in Malaysia remains a matter of concern. The predictors of cervical cancer screening uptake were women with children, women with good knowledge of cervical cancer symptoms, married women and those receiving support from their husbands. Thus, efforts by the government to boost the uptake of cervical cancer screening should target these groups based on the predictors of positive uptake.

\section{ACKNOWLEDGEMENTS}

This rural community survey was conducted under the subtheme 'Women's Health Issues' for the community residency programme by third-year MBBS students. We would like to thank the students and lecturers at the Department of Social and Preventive Medicine, Faculty of Medicine, University of Malaya, Kuala Lumpur, Malaysia, as well as respondents from the selected villages of Northern Perak who participated in the study.

\section{REFERENCES}

1. Ferlay J, Shin HR, Bray F, et al. Estimates of worldwide burden of cancer in 2008: GLOBOCAN 2008. Int J Cancer 2010; 127:2893-917.

2. Ministry of Health Malaysia. Malaysia Cancer Statistics-Data and Figure 2007. Malaysia: National Cancer Registry Report, 2011.

3. Forouzanfar $\mathrm{MH}$, Foreman $\mathrm{KJ}$, Delossantos AM, et al. Breast and cervical cancer in 187 countries between 1980 and 2010: a systematic analysis. Lancet 2011; 378:1461-84.

4. Ministry of Health Malaysia. Clinical Practice Guidelines: Management of Cervical Cancer. Malaysia: Ministry of Health Malaysia, 2003.

5. Ministry of Health Malaysia. The Third National Health and Morbidity Survey (NHMS III) 2006, Volume 2. Institute for Public Health (IPH), 2008.

6. Chee HL, Rashidah S, Shamsuddin K, Intan O. Factors related to the practice of breast self examination (BSE) and Pap smear screening among Malaysian women workers in selected electronics factories. BMC Womens Health 2003; 3:3.

7. Abdullah F, Aziz NA, Su TT. Factors related to poor practice of Pap smear screening among secondary school teachers in Malaysia. Asian Pac J Cancer Prev 2011; 12:1347-52.

8. Tan YY, Hesham R, Qodriyah HM. Knowledge and attitude of university 
students in health sciences on the prevention of cervical cancer. Med J Malaysia 2010; 65:53-7.

9. Denny L, Quinn M, Sankaranarayanan R. Chapter 8: Screening for cervical cancer in developing countries. Vaccine 2006; 24 suppl 3:S3/71-7.

10. Blomberg K, Tishelman C, Ternestedt BM, et al. How can young women be encouraged to attend cervical cancer screening? Suggestions from faceto-face and internet focus group discussions with 30-year-old women in Stockholm, Sweden. Acta Oncol 2011; 50:112-20.

11. Department of Statistics Malaysia. Population Distribution by Local Authority Areas and Mukims, 2010 [online]. Available at: www.statistics. gov.my/portal_lama/download_Population/files/population/03ringkasan_ kawasan_PBT_Jadual1.pdf. Accessed January 22, 2013.

12. Rebolj M, van Ballegooijen M, Berkers LM, Habbema D. Monitoring a national cancer prevention program: successful changes in cervical cancer screening in the Netherlands. Int J Cancer 2007; 120:806-12.

13. Leung SS, Leung I. Cervical cancer screening: knowledge, health perception and attendance rate among Hong Kong Chinese women. Int J Womens Health 2010; 2:221-8.

14. Al-Naggar RA, Low WY, Isa ZM. Knowledge and barriers towards cervical cancer screening among young women in Malaysia. Asian Pac J Cancer Prev 2010; 11:867-73.

15. Paolino M, Arrossi S. Women's knowledge about cervical cancer, Pap smear and human papillomavirus and its relation to screening in Argentina. Women Health 2011; 51:72-87.

16. Uysal A, Birsel A. Knowledge about cervical cancer risk factors and pap testing behaviour among Turkish women. Asian Pac J Cancer Prev 2009; 10:345-50.

17. Liao CC, Wang HY, Lin RS, Hsieh CY, Sung FC. Addressing Taiwan's high incidence of cervical cancer: factors associated with the Nation's low compliance with Papanicolaou screening in Taiwan. Public Health 2006; 120:1170-6.

18. Erbil N, Tezcan Y, Gür EN, Yildirim M, Aliş N. Factors affecting cervical screening among Turkish women. Asian Pac J Cancer Prev 2010; 11:1641-4.
19. Kivistik A, Lang K, Baili P, Anttila A, Veerus P. Women's knowledge about cervical cancer risk factors, screening, and reasons for non-participation in cervical cancer screening programme in Estonia. BMC Womens Health $2011 ; 11: 43$

20. Hansen BT, Hukkelberg SS, Haldorsen T, et al. Factors associated with nonattendance, opportunistic attendance and reminded attendance to cervical screening in an organized screening program: a cross-sectional study of 12,058 Norwegian women. BMC Public Health 2011; 11:264.

21. Lofters AK, Moineddin R, Hwang SW, Glazier RH. Predictors of low cervical cancer screening among immigrant women in Ontario, Canada. BMC Womens Health 2011; 11:20.

22. Brouwers MC, De Vito C, Bahirathan L, et al. Effective interventions to facilitate the uptake of breast, cervical and colorectal cancer screening: an implementation guideline. Implement Sci 2011; 6:112.

23. Wong LP, Wong YL, Low WY, Khoo EM, Shuib R. Knowledge and awareness of cervical cancer and screening among Malaysian women who have never had a Pap smear: a qualitative study. Singapore Med J 2009; 50:49-53.

24. Mupepi SC, Sampselle CM, Johnson TR. Knowledge, attitudes, and demographic factors influencing cervical cancer screening behavior of Zimbabwean women. J Womens Health (Larchmt) 2011; 20:943-52.

25. Osborne C, Ostir GV, Du X, Peek MK, Goodwin JS. The influence of marital status on the stage at diagnosis, treatment, and survival of older women with breast cancer. Breast Cancer Res Treat 2005; 93:41-7.

26. e Silva IT, Griep RH, Rotenberg L. Social support and cervical and breast cancer screening practices among nurses. Rev Lat Am Enfermagem 2009; 17:514-21

27. Gamarra CJ, Paz EP, Griep RH. Social support and cervical and breast cancer screening in Argentinean women from a rural population. Public Health Nurs 2009; 26:269-76.

28. Seow A, Huang J, Straughan PT. Effects of social support, regular physician and health-related attitudes on cervical cancer screening in an Asian population. Cancer Causes Control 2000; 11:223-30.

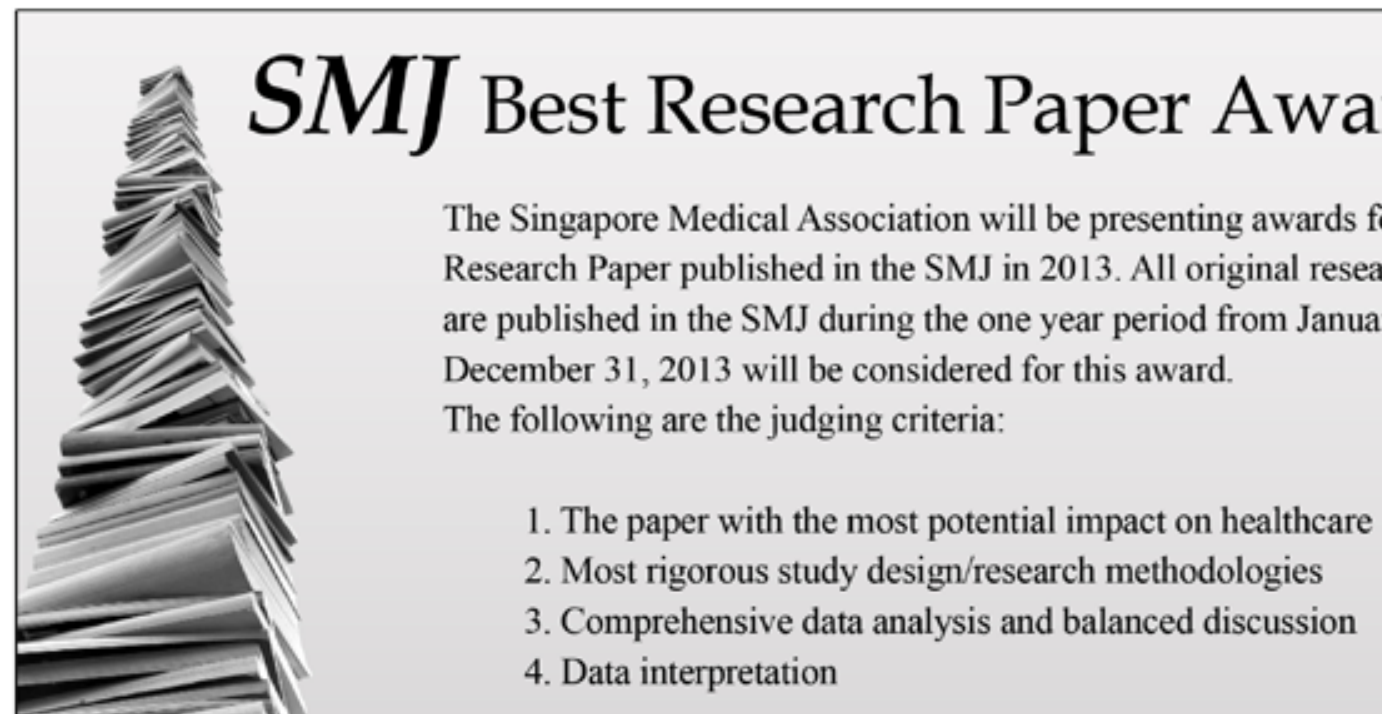

Distinguished members of the medical profession will be invited to serve on our panel of judges for selecting the winning papers. The authors of the winning papers selected by our panel of judges will receive cash prizes for the first, second and third places. Prize winners will also receive a commemorative trophy and certificate.

Thank you for your support of the SMJ.

The quality of our journal depends on the quality of your submissions. 